\title{
Risk Factors and Hypothesis for Posttraumatic Stress Disorder (PTSD) in Post Disaster Survivors
}

\author{
Frank Huang-Chih Chou ${ }^{1}$ and Chao-Yueh $\mathrm{Su}^{2}$ \\ ${ }^{1}$ Department of Community Psychiatry, Kai-Suan Psychiatric Hospital, Kaohsiung, \\ ${ }^{2}$ Department of Nursing, I-Shou University, Kaohsiung City, \\ Taiwan
}

\section{Introduction}

Disasters, both natural and man-made, affect millions of people around the world every year. Natural disasters (e.g., earthquakes and hurricanes) and man-made disasters (e.g., traffic accidents, acts of terrorism and wars) can cause mental trauma with long-lasting consequences (Chou et al., 2005; Chou et al., 2007). The impact of a mass disaster or man-made trauma on the individual is a composite of two major elements: the catastrophic event itself and the vulnerability of those people affected by the event. To this end, post-disaster survivors need specific, systemic evaluation and management (Sapir, 1993).

\section{The relationship between disasters and Posttraumatic Stress Disorder (PTSD)}

Breslau et al. (1991) estimated that $6 \%$ to $7 \%$ of the US population is exposed to disaster or trauma every year, while Wang et al. (2000) showed that natural disasters affect an average of approximately 200 million people in China every year, several thousand of whom do not survive. In the aftermath of these catastrophic events, PTSD is one of the most common psychiatric diseases suffered by post-disaster survivors.

The prevalence of PTSD ranged from 3.0\% to 34.3\% in Taiwan after the 1999 earthquake (Chou et al., 2004a,b), it was approximately 25\% in Turkey after the 1999 earthquake (Tural et al., 2004), and it was reported as 74\% in Armenia after the 1988 earthquake (Armen, 1993). In a systemic review of the literature, Andrews, Brewin, Philpott, \& Stewart (2007) found that delayed-onset PTSD in the absence of any prior symptoms was rare, whereas delayed onset that represented exacerbations or reactivations of prior symptoms accounted for, on average, $38.2 \%$ and $15.3 \%$ of military and civilian cases of PTSD, respectively. Generally, the lifetime and current prevalence rates for psychiatric disorders range anywhere from $1 \%$ to 74\% (Breslau, Davis, Andreski, \& Peterson, 1991; Carr et al., 1995; Chang et al., 2003; Chou et al., 2003; Tainaka et al., 1998), with women twice as likely as men to be affected. Furthermore, women report more symptoms of anxiety and depression than men (Chou et al., 2003; Chang et al., 2003). 


\section{The introduction of PTSD}

Clinicians have recognized the juxtaposition of acute mental syndromes to traumatic events for more than 200 years. Observations of trauma-related syndromes were documented following the Civil War, and early psychoanalytic writers, including Freud, noted the relation between neurosis and trauma (Kaplan \& Sadock, 1999).

The American Psychiatric Association (APA) (1952) published the “Diagnostic and statistical manual of mental disorders, first edition, DSM-I" and included in that edition gross stress reactions. However, the term PTSD was not included in the publications until the DSM-III in 1980 (Jones et al., 2003). It was then revised in the DSM-III-R (1987) and the DSM-IV (1994). According to the DSM-IV diagnostic criteria, PTSD has three core psychopathologies: (a) reexperience, (b) numbness and avoidance, and (c) hyper-arousal. The DSM-IV diagnostic criteria for PTSD allow clinicians to specify if the disorder is chronic, that is, the symptoms have lasted three months or more, or if the disorder exhibits delayed onset, that is, the onset of the symptoms was six months or more after the stressful event (Su, Tsai, Chou, et al., 2010). PTSD is an anxiety disorder that develops after a person has been exposed to a severe, life-threatening trauma. Its symptoms include a re-experiencing or reliving of the event, an avoidance or numbness toward the event, and/or hyper-arousal (American Psychiatric Association, 1994). Accordingly, PTSD is characterized by two special memory phenomena. The first is a facilitated memory of the traumatic event, including flashbacks and nightmares. The second is an inhibited memory involving the inability to voluntarily recall important aspects of the trauma (Hellawell \& Brewin, 2002; Thomaes et al., 2009). These observations imply that emotional memory dysfunctions are key components in PTSD, and they include involuntary retrieval such as flashbacks and intrusions, exaggerated and context-independent fear, failure to integrate the trauma as a coherent episode into an autobiographical memory, and impaired fear memory extinction (Wolf, 2008).

\section{PTSD with psychiatric co-morbidity}

The majority of the research (Goenjian et al., 2000; Green, Lindy, Grace, \& Leonard, 1992; Maj et al., 1989; McFarlane \& Papay, 1992; Rubonis \& Bickman, 1991) provides evidence of psychological sequelae that includes PTSD, major depressive episodes, sleep disorder, anxiety, and substance abuse after disasters. Furthermore, major depressive episodes and PTSD are the most common disaster-related psychiatric diagnoses and are strongly associated with one another (McFarlane \& Papay, 1992; Goenjian et al., 2000; Green et al., 1992). Individuals confronted with disasters or major stressors exhibit greater psychological impairment and are more vulnerable to psychiatric diseases (Chou et al., 2005). The incidence of PTSD is higher than that of other major depressive episodes in the majority of the studies (Bromet \& Dew, 1995; Chou et al., 2003; Chou et al., 2004a; Chou et al., 2004b; Chou et al., 2005; Davidson et al., 1991; Davidson 1995; Goenjian et al., 1994; Green et al., 1992; Sharan et al., 1996). In contrast to natural disasters, however, higher co-morbidity has been found with combat-related PTSD. Such co-morbidity includes drug and alcohol abuse, antisocial personality disorder, somatization disorder, and depression, and it is particularly prevalent when determined from an historical perspective (Green et al., 1992). PTSD can be triggered by a variety of traumatic events and is strongly associated with all other examined mental disorders (Brady, Killeen, Brewerton, \& Lucerini, 2000; Goenjian et al., 2000; 
Perkonigg, Kessler, Storz, Wittchen, 2000). For example, the combination of PTSD and panic and phobic disorders is an important predictor for PTSD chronicity (McFarlane \& Papay, 1992; Ursano, Kao, \& Fullerton, 1992). Furthermore, the rate of psychopathology is higher in post-disaster groups than in either the same groups prior to trauma or in control groups (Maj et al., 1989; Rubonis \& Bickman, 1991).

\section{Psychiatric studies of post-Chi-Chi earthquake survivors}

Researchers focusing on survivors of the Chi-Chi earthquake in Taiwan (Su, Chou, Lin, Tsai, 2010) have found evidence of psychological sequelae that includes posttraumatic stress disorder (PTSD), major depressive disorder, sleep disorder, anxiety, and substance abuse (Chou et al., 2004a, 2004b, 2005, 2007; Chen et al., 2001; Chang et al., 2002; Lai et al., 2004; Hsu et al., 2002; Kuo et al., 2003; Liu et al., 2006; Tsai et al., 2007; Wu et al., 2006; Yang et al., 2003). The quality of life for survivors of traumatic events who develop psychiatric illnesses or impairments is worse than that for survivors without any psychiatric illness (Chou et al., 2004b; Tsai et al., 2007; Wu et al., 2006). In addition, rescue workers such as nurses, fire fighters, and soldiers may develop physical or mental impairments (Chang et al., 2008; Liao et al., 2002; Shih et al., 2002; Yeh et al., 2002). We used PubMed to identify Chi-Chi earthquake-related papers published through June of 2009. All of the Chi-Chi earthquake papers related to psychiatry are summarized in Table 1 (cited from $\mathrm{Su}$, Chou, Lin, Tsai, 2011).

\section{The risk factors of PTSD}

Researchers who study risk factors for PTSD have identified aspects of demographic data, psychological factors, psychiatric symptoms, and post-trauma social resource factors as important factors that contribute to the development of the disease.

\subsection{Demographic data}

Some researchers who have examined gender differences suggest that females are more likely than males to develop PSTD (Chou et al., 2005; Helzer, Robins, \& McEvoy, 1987; Johnson \& Thompson, 2008; Lazaratou et al., 2008). A possible explanation for this is the specific reactions that result from feminine characteristics to a traumatic event (Chou, Tsai, Wu, Su, \& Chou, 2006). Additionally, there are previous studies that have associated old age with an increased risk of developing PTSD (Goenjian et al., 1994; Lewin, Carr, Webster, 1998). However, a recent study has suggested contradictory results (Lazaratou et al., 2008).

\subsection{Biological factors}

Neuroendocrine data provide evidence of insufficient glucocorticoid signaling in stressrelated neuropsychiatric disorders, while Nutt (2000) has suggested that individuals develop PTSD due to neuroendocrine dysregulation. Furthermore, impaired feedback regulation of relevant stress responses, especially immune activation/inflammation, may, in turn, contribute to stress-related pathology that includes alterations in behavior, insulin sensitivity, bone metabolism, and acquired immune responses (Raison \& Miller, 2003). Because the hypothalamic-pituitary gland-adrenal axis (HPA) regulates hormone reactions during stress, PTSD severity seems to decrease when individuals exposed to traumatic 


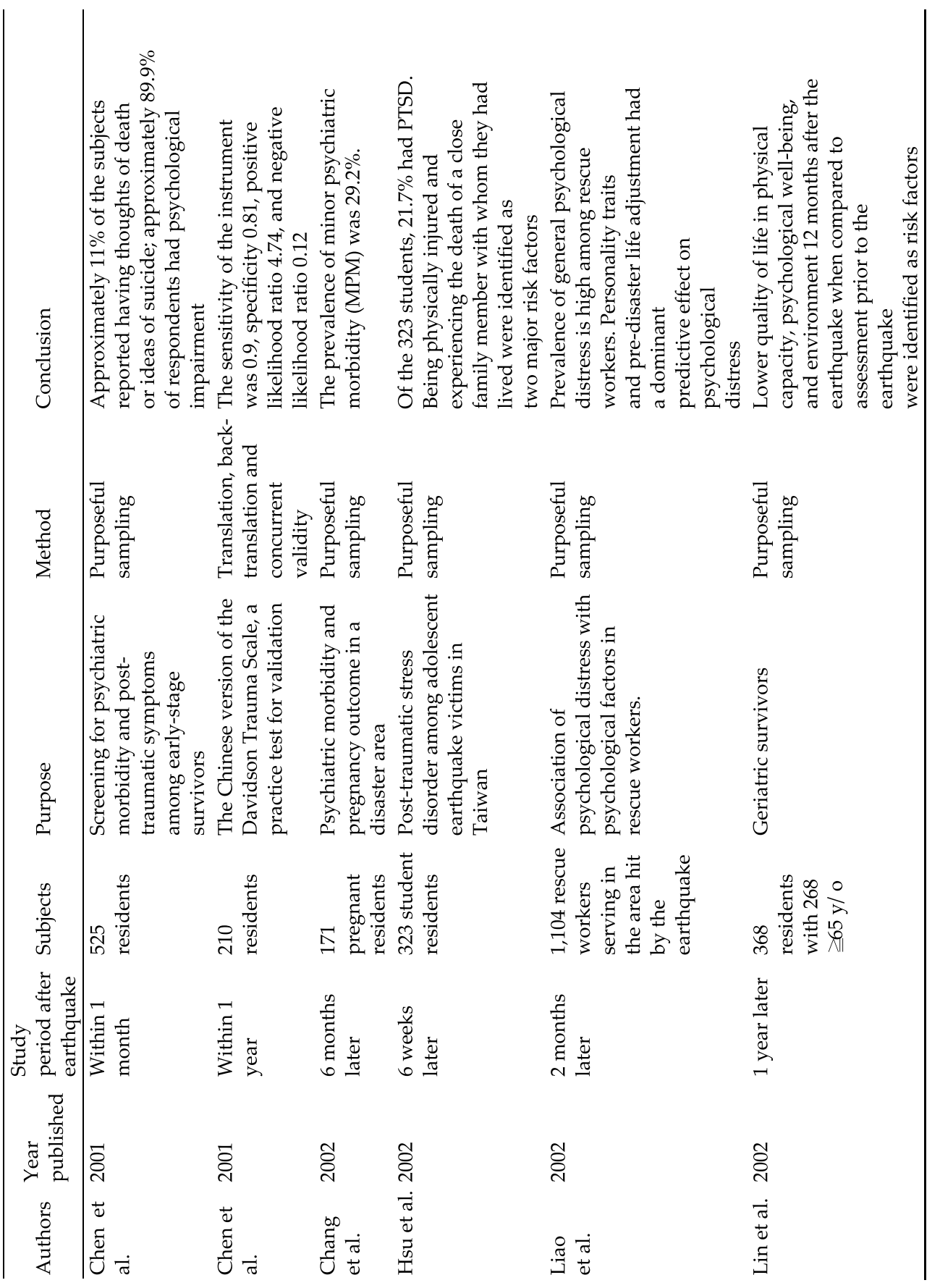




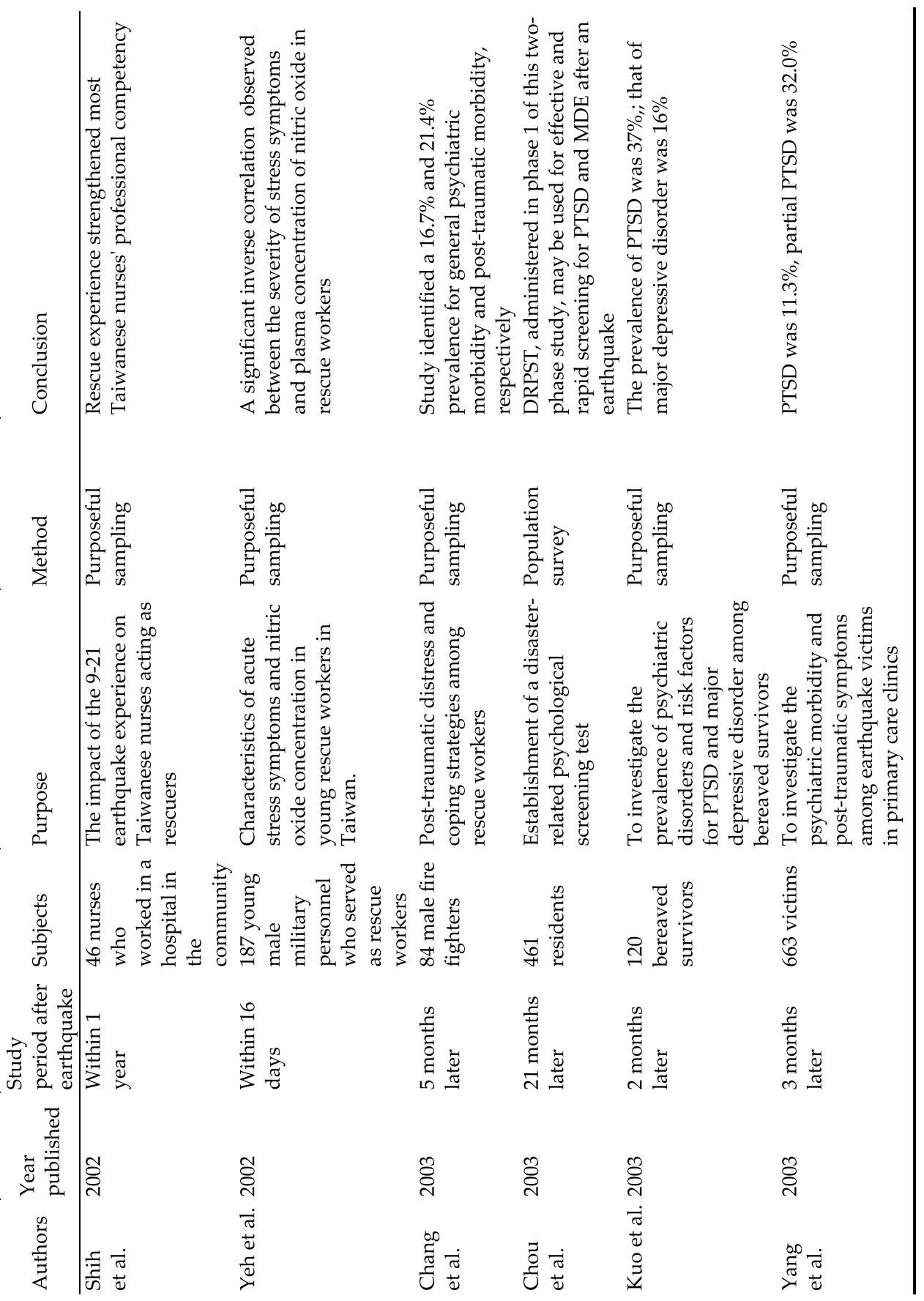




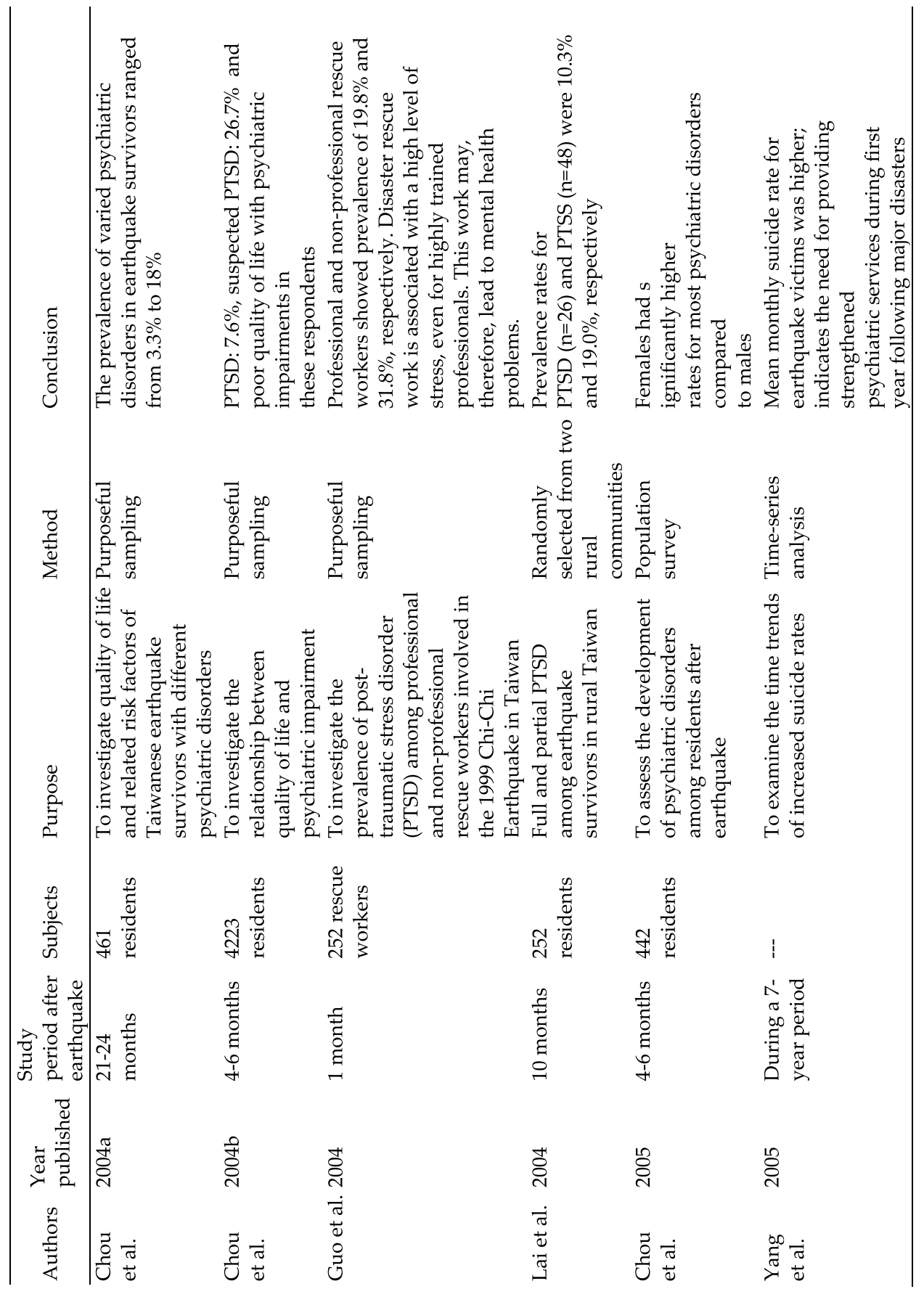




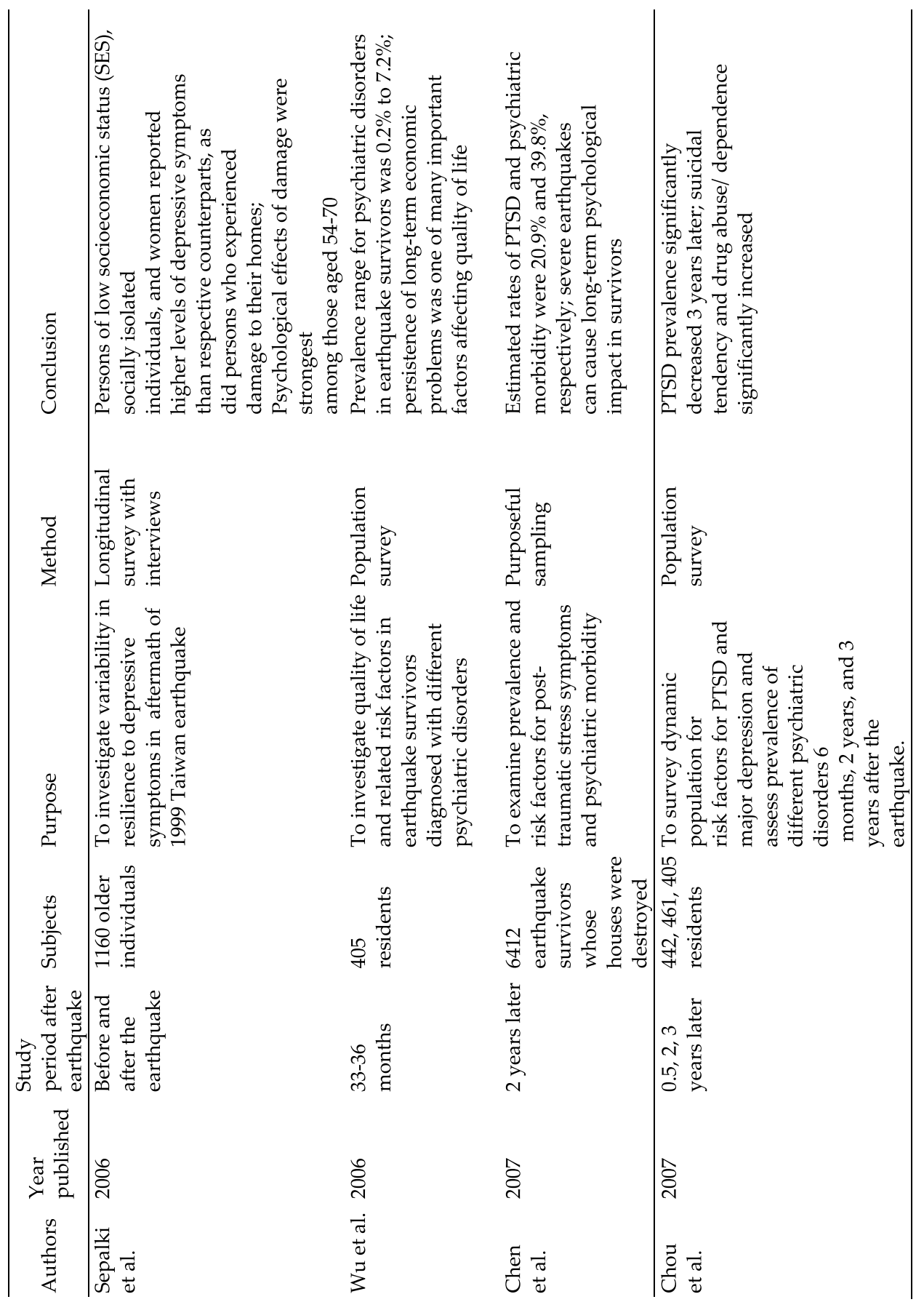




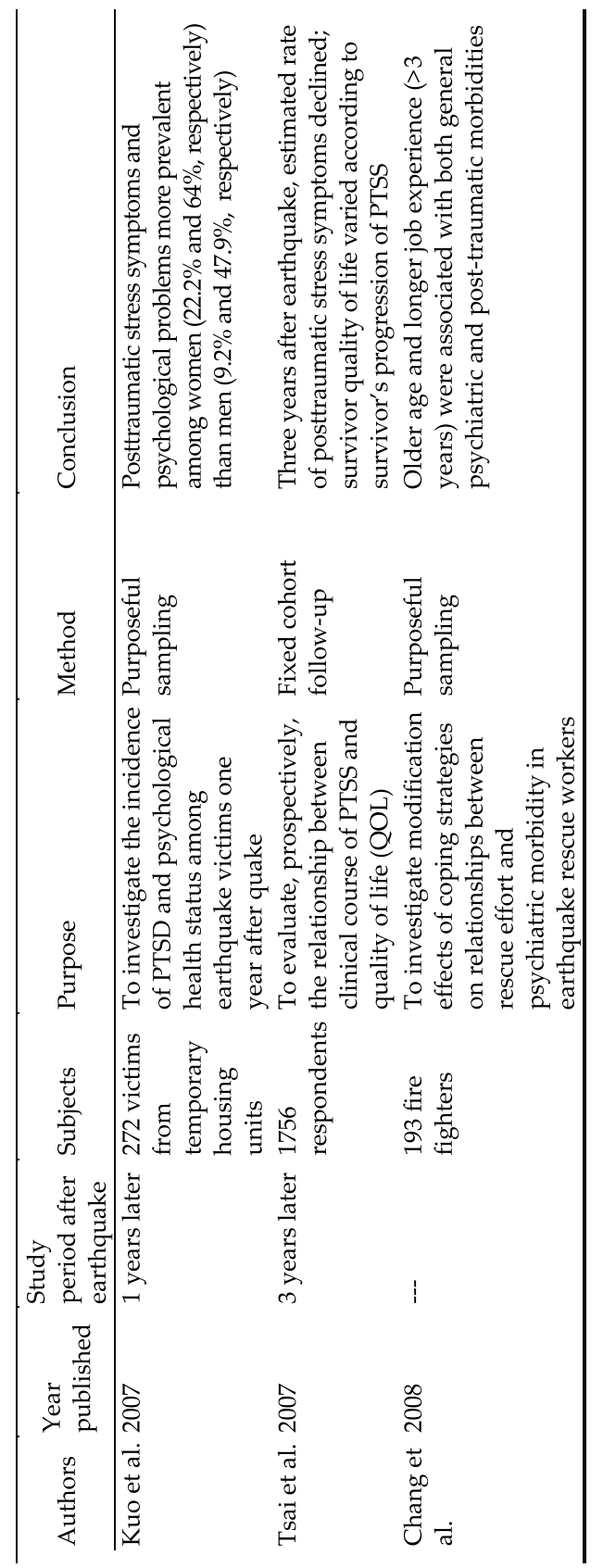

Cited from Su et al. (2011) under permission

Table 1. Summary of Chi-Chi earthquake papers related to psychiatry (PubMed search through June 2009) (cited from Su et al., with permission) 
events experience decreased stress levels. Thabet \& Vostanis, (2000) and Gurvits et al. (1997) found more positive soft neurological signs in PTSD participants than in participants who experienced similar trauma but did not develop PTSD. Many trauma victims complain of memory impairment, such as difficulty remembering daily activities, frequent compulsive recall of the traumatic event in detail, memory gaps, island-like memory, difficulties with declarative memory, and intrusive memories. Anderson et al. (2004) used functional magnetic resonance imaging (MRI) to identify the neural systems involved in keeping unwanted memories out of one's awareness. Controlling unwanted memories is associated with increased dorsolateral prefrontal activation (DLPF), reduced hippocampal activation, and impaired retention of those memories. Both prefrontal cortical and right hippocampal activations predicted the magnitude of forgetting. These results confirm the existence of an active forgetting process and establish a neurobiological model for guiding inquiry into motivated forgetting.

There are still gaps in our understanding of the genetic underpinnings of PTSD. For example, while Stein et al. (2002) have found moderate hereditary factors in individuals with PTSD symptoms, no single gene that causes PTSD has been identified.

\subsection{Psychological factors and psychiatric symptoms}

Meyer et al. (1999) indicated that some psychiatric symptoms and disorders are risk factors for PTSD (Meyer, Taiminen, Vuori, Aijälä, Helenius, 1999). For example, certain personality traits, such as neuroticism and introversion, are associated with an increased risk of PTSD (Lewin, Carr, \& Webster, 1998; McFarlane, 1988) while some studies indicate that certain psychiatric disorders may be predictive of chronic PTSD (Engdahl, Dikel, Eberly, \& Blank, 1998; McFarlane \& Papay, 1992). Then again, other studies have examined the long-term course of PTSD. A longitudinal analysis of the mental health of school children after the great Hanshin Awaji earthquakes indicated that some survivors' psychological reactions emerged early and disappeared early (i.e., within two years after the disaster); however, this is contrary to findings from other studies (Shioyama et al., 2000). Lazaratou et al. (2008) have found that greater numbers of PTSD symptoms emerged during the first 6 months after the earthquake and were associated with a greater impact on the victims' lives 50 years after the event. Uemoto et al. (2000) posited that the best predictor of recovery from chronic PTSD was the initial level of post-traumatic reaction immediately after the accident. However, few data are available on the long-term effects caused by a disaster (Chou et al., 2007).

\subsection{Post-trauma social resource factors}

Inadequate social support after the trauma adds to the risk of developing PTSD (Chou et al., 2004a; Wang et al., 2000). Not surprisingly, higher levels of post-disaster life events are also related to the risk of developing PTSD (Chang, Connor, Lai, Lee, \& Davidson, 2005). Similarly, social stressors such as economic or marital issues or a disruption of one's daily life, including relocation, the death of an intimate partner, or other significant loss problems are associated with a greater risk for developing PTSD.

\section{Hypothesis for PTSD}

Hobfoll's conservation of resources (COR) model has been well supported by previous studies on natural disasters (Sumer, Karanci, Berument, \& Gunes, 2005). According to 
Hobfoll's conservation of resources stress theory (Hobfoll, 1989; Chou et al., 2007), resource loss is an important determinant of individual stress and physical and mental health, including PTSD. Brewin et al. (2000) also found that the effect sizes of all risk factors were modest. Factors operating during or after the trauma (e.g., trauma severity, lack of social support, and additional life stress), however, had somewhat stronger effects than did pretrauma factors.

Consequently, multiple risk factors constitute a network that results in psychiatric illness. According to Hobfoll's conservation of resources theory, resource loss is an important determinant of individual stress and physical and mental health, including PTSD. Our hypothesis states that an individual reaches a sub-threshold of psychiatric illness and then develops the illness due to a decreasing availability of resources, an accumulation of risk factors, and/or a major stressful event. Furthermore, unresolved, sub-clinical psychiatric symptoms caused by a disaster or major life event may increase a survivor's sensitivity to future stresses. When faced with stress, frustration (e.g., life events), or traumatic events (e.g., brain damage or deprivation of internal or external resources) individuals, either suddenly or gradually, become more vulnerable to psychiatric impairment and diseases such as PTSD. An individual might reach a sub-threshold of PTSD and then develop the illness due to a decreased availability of resources, an accumulation of risk factors (personality traits, poor social interactions, etc.) or a major stressful event. Furthermore, unresolved, subclinical psychiatric symptoms caused by a disaster may increase a survivor's sensitivity to future stresses. Other factors that tend to increase an individual's vulnerability to psychiatric problems include brain damage, heredity, personality traits, life events, and social interactions.

\section{The treatment and rehabilitation of PTSD}

Treatment or rehabilitation efforts should concentrate not only on severe psychiatric symptoms, emotional disturbances and personality traits or disorders, but also on interpersonal and social-environmental interactions. To treat PTSD, clinicians only use drugs and do not provide psychosocial treatment; thus, they cannot meet the true needs of the survivor. Based on the bio-psychosocial causation model of psychiatric disease as it applies to public health, we propose a model of the causation of PTSD. Issues related to PTSD that are most in need of further study include biological causation, psychosocial recovery, and long-term evaluation of psychological rehabilitation.

\section{Conclusion}

Although changes in emotional, cognitive, behavioral, and biologic states are transitory for most individuals after a catastrophe or major trauma, psychological trauma may persist much longer in some victims. While the psychological profiles of these victims are often altered, given their vivid and repetitive recollection of the traumatic events (Chou et al., 2004b; Chou et al., 2005; Lin et al., 2002), Wang et al. (2000) determined that prompt and effective post-disaster intervention might mitigate the impact of initial exposure and reduce the probability of PTSD occurrence. Issues related to PTSD most in need of further study include biological causation, psychosocial recovery, and long-term evaluation of psychological rehabilitation. 


\section{References}

American Psychiatric Association (1994). Diagnostic and Statistical Manual of Mental DisordersFourth Edition. Washington, DC: American Psychiatric Association.

Anderson MC, Ochsner KN, Kuhl B, Cooper J, Robertson E, Gabrieli SW, et al. (2004). Neural systems underlying the suppression of unwanted memories. Science. 303: 232-235.

Andrews B, Brewin CR, Philpott R, Stewart L (2007). Delayed-onset posttraumatic stress disorder: a systematic review of the evidence. Am J Psychiatry. 164:1319-26.

Armen G. (1993). A mental health relief programme in Armenia after the 1988 earthquake: implementation and clinical observations. Br J Psychiatry. 163: 230-239.

Brady KT, Killeen TK, Brewerton T, Lucerini S. (2000). Comorbidity of psychiatric disorders and posttraumatic stress disorder. J Clin Psychiatry, 61(Suppl)7: 22-32.

Breslau N, Davis GC, Andreski P, Peterson E. (1991). Traumatic events and post-traumatic stress disorder in an urban population of young adults. Arch Gen Psychiatry. 48: 216-222.

Brewin CR, Andrews B, Valentine JD. (2000). Meta-analysis of risk factors for posttraumatic stress disorder in trauma-exposed adults. J Consult Clin Psychol. 68: 748-766.

Carr VJ, Lewin TJ, Webster RA, Hazell PL, Kenardy JA, Carter GL. (1995). Psychosocial sequlae of the 1989 Newcastle earthquake: I. Community disaster experiences and psychological morbidity 6 months post-disaster. Psychol Med. 25: 539-555.

Chang CM, Connor KM, Lai TJ, Lee LC, Davidson JR. (2005). Predictors of posttraumatic outcomes following the 1999 Taiwan earthquake. J Nerv Ment Dis. 193: 40-46.

Chang CM, Lee LC, Connor KM, Davidson JR, Jeffries K, Lai TJ. (2003). Posttraumatic distress and coping strategies among rescue workers after an earthquake. J Nerv Ment Dis, 191:391-398.

Chang CM, Lee LC, Connor KM, Davidson JR, Lai TJ. (2008). Modification effects of coping on post-traumatic morbidity among earthquake rescuers. Psychiatry Res. 158(2): 164-171.

Chang HL, Chang TC, Lin TY, Kuo SS. (2002). Psychiatric morbidity and pregnancy outcome in a disaster area of Taiwan 921 earthquake. Psychiatry Clin Neurosci. 56: 139-144.

Chen CC, Yeh TL, Yang YK, Chen SJ, Lee IH, Fu LS, et al. (2001). Psychiatric morbidity and post-traumatic symptoms among survivors in the early stage following the 1999 earthquake in Taiwan. Psychiatry Res. 105: 13-22.

Chou FH, Chou P, Lin C, Su TT, Ou-Yang WC, Chien IC, et al. (2004b). The relationship between quality of life and psychiatric impairment for a Taiwanese community post earthquake. Qual Life Res. 13: 1089-1097.

Chou FH, Chou P, Su TT, Ou-Yang WC, Chien IC, Lu MK, et al. (2004a). Survey of quality of life and related risk factors for a Taiwanese village population 21 months after an earthquake. Aust N Z J Psychiatry. 38: 358-364.

Chou FH, Su TT, Chou P, Ou-Yang WC, Lu MK, Chien IC. (2005). Survey of Psychiatric Disorders in a Taiwan Village Population Six Months after a Major Earthquake. J Formosan Med Association. 104: 308-317.

Chou FH, Su TT, Ou-Yang WC, Chien IC, Lu MK, Chou P. (2003). Establishment of a disaster-related psychological screening test. Aust NZ J Psychiatry. 37(1): 97-103. 
Chou FH, Tsai KY, Wu HC, Su TT, Chou P. (2006). Disaster and Posttraumatic Stress Disorder. Taiwanese J Psychiatry. 20: 85-103.

Chou FH, Wu HC, Chou P, Su CY, Tsai KY, Chao SS, et al. (2007). Epidemiologic Psychiatric Studies on Postdisaster Impact among Chi-Chi Earthquake Survivors in Yu-Chi, Taiwan. Psychiatry Clin Neurosci. 61: 370-378.

Davidson JRT, Hughes DL, Blazer DG, George LK (1991). Posttraumatic stress disorder in the community: An epidemiological study. Psychol Med. 21:713.

Davidson JRT. (1995). Posttraumatic stress disorder and acute stress disorder, in Comprehensive Textbook of Psychiatry, 6th ed. Edited by Kaplan HI, Sadock BJ. Baltimore, Williams \& Wilkins, 1227-1236.

Engdahl B, Dikel TN, Eberly R, Blank A Jr. (1998). Comorbidity and course of psychiatric disorders in a community sample of former prisoners of war. Am J Psychiatry. 155: 1740-1745.

Goenjian AK, Najarian LM, Pynoos RS, Steinberg AM, Manoukian G, Tavosian A, et al. (1994). Posttraumatic stress disorder in elderly and younger adults after the 1988 earthquake in Armenia. Am J Psychiatry. 151: 895-901.

Goenjian AK, Steinberg AM, Najarian LM, Fairbanks LA, Tashjian M, Pynoos RS. (2000). Prospective study of posttraumatic stress, anxiety, and depressive reactions after earthquake and political violence. Am J Psychiatry. 157: 911-916.

Green BL, Lindy JD, Grace MC, Leonard AC. (1992). Chronic posttraumatic stress disorder and diagnostic comorbidity in a disaster sample. J Nerv Ment Dis. 180: 760-766.

Gurvits TV, Gilbertson MW, Lasko NB, Orr SP, Pitman RK. (1997). Neurological status of combat veterans and adult survivors of sexual abuse PTSD. Ann N Y Acad Sci. 821: 468-471.

Hellawell SJ, Brewin CR (2002). A comparison of flashbacks and ordinary autobiographical memories of trauma: cognitive resources and behavioural observations. Behaviour Research \& Therapy, 40(10): 1143-1156.

Helzer JE, Robins LN, McEvoy L. (1987). Posttraumatic stress disorder in the general population : findings of the Epidemiologic Catchment Area Survey. N Engl J Med; 317:1630-4.

Hobfoll SE(1989): Conservation of Resources: a new attempt at conceptualizing stress. The American Psychologist 44: 513-524.

Hsu CC, Chong MY, Yang P, Yen CF. (2002). Posttraumatic stress disorder among adolescent earthquake victims in Taiwan. J Am Acad Child Adolesc Psychiatry. 41: 875-881.

Johnson H, Thompson A. (2008). The development and maintenance of post-traumatic stress disorder (PTSD) in civilian adult survivors of war trauma and torture: a review. Clin Psychol Rev. 28: 36-47.

Jones E, Vermaas RH, Mccartney H, et al. (2003). Flashbacks and post-traumatic stress disorder: the genesis of a 20th-century diagnosis. Br J Psychiatry. 158-63.

Kaplan, Sadock's (1999). Comprehensive Textbook of Psychiatry, 7th ed.

Kuo CJ, Tang HS, Tsay CJ, Lin SK, Hu WH, Chen CC. (2003). Prevalence of psychiatric disorders among bereaved survivors of a disastrous earthquake in taiwan. Psychiatr Serv. 54: 249-251.

Lai TJ, Chang CM, Connor KM, Lee LC, Davidson JR. (2004). Full and partial PTSD among earthquake survivors in rural Taiwan. J Psychiatr Res. 38: 313-322. 
Lazaratou H, Paparrigopoulos T, Galanos G, Psarros C, Dikeos D, Soldatos C. (2008). The psychological impact of a catastrophic earthquake: a retrospective study 50 years after the event. J Nerv Ment Dis. 196: 340-344.

Lewin TJ, Carr VJ, Webster RA. (1998). Recovery from post-earthquake psychological morbidity: who suffers and who recovers? Aust N Z J Psychiatry. 32: 15-20.

Liao SC, Lee MB, Lee YJ, Weng T, Shih FY, Ma MH. (2002). Association of psychological distress with psychological factors in rescue workers within two months after a major earthquake. J Formosan Med Association. 101(3): 169-176.

Lin MR, Huang W, Huang C, Hwang HF, Tsai LW, Chiu YN. (2002). The impact of the ChiChi earthquake on quality of life among elderly survivors inTaiwan:Abefore and after study. Qual Life Res. 11: 379-388.

Liu A, Tan H, Zhou J, Li S, Yang T, Wang J, et al. (2006). An epidemiologic study of posttraumatic stress disorder in flood victims in Hunan China. Can J Psychiatry. 51(61): 350-354.

Maj M, Starace F, Crepet P, Lobrace S, Veltro F, De Marco F, et al. (1989). Prevalence of psychiatric disorders among subjects exposed to a natural disaster. Acta Psychiatr Scand. 79: 544-549.

McFarlane AC, Papay P. (1992). Multiple diagnoses in posttraumatic stress disorder in the victims of a natural disaster. J Nerv Ment Dis. 180: 498-504.

McFarlane AC. (1988). The longitudinal course of posttraumatic morbidity. The range of outcomes and their predictors. J Nerv Ment Dis. 176(1): 30-39.

Meyer H, Taiminen T, Vuori T, Aijälä A, Helenius H. (1999). Posttraumatic stress disorder symptoms related to psychosis and acute involuntary hospitalization in schizophrenic and delusional patients. J Nerv Ment Dis. 187: 343-352.

Nutt DJ. (2000). The psychobiology of posttraumatic stress disorder. J Clin Psychiatry. 61(Suppl): 24-9; discussion 30-2.

Perkonigg A, Kessler RC, Storz S, Wittchen HU. (2000). Traumatic events and post-traumatic stress disorder in the community: prevalence, risk factors and comorbidity. Acta Psychiatr Scand. 101: 46-59.

Raison CL, Miller AH. (2003). When not enough is too much: the role of insufficient glucocorticoid signaling in the pathophysiology of stress-related disorders. Am J Psychiatry. 160: 1554-1565.

Rubonis AV, Bickman L. (1991). Psychological impairment in the wake of disaster: the disaster-psychopathology relationship. Psychol Bull. 109: 384-399.

Sapir DG. (1993). Natural and man-made disasters: the vulnerability of women-headed households and children without families. World Health Status Quartly. 46: 227233.

Sharan P, Chaudhary G, Kavathekar SA, Saxena S. (1996). Preliminary report of psychiatric disorders in survivors of a severe earthquake. Am J Psychiatry; 153:556-558.

Shih FJ, Liao YC, Chan SM, Duh BR, Gau ML. (2002). The impact of the 9-21 earthquake experiences of Taiwanese nurses as rescuers. Social Science of Medicine. 55: 659672.

Shioyama A, Uemoto M, Shinfuku N, Ide H, Seki W, Mori S, et al. (2000). The mental health of school children after the Great Hanshin-Awaji Earthquake: II. Longitudinal analysis. Seishin Shinkeigaku Zasshi. 102: 481-497. 
Stein MB, Jang KL, Taylor S, Vernon PA, Livesley WJ. (2002). Genetic and environmental influences on trauma exposure and posttraumatic stress disorder symptoms: a twin study. Am J Psychiatry. 159: 1675-1681.

Su CY, Chou FH, Lin WK, Tsai KY. (2011). The Establishment of a Standard Operation Procedure (SOP) for Psychiatric Service after an Earthquake. Disasters. 2011;35 (3):587-605.

Su CY, Tsai KY, Chou FH, Liu RY, Lin WK. (2010) A Three-year, Follow-up Study of the 8 Psychosocial Predictors of Delayed and Unresolved PTSD in Taiwan Chi-Chi, Earthquake Survivors. Psychiatry Clin Neurosci 2010; 64(3):239-48.

Sumer N, Karanci AN, Berument SK, Gunes H. (2005). Personal resources, coping selfefficacy, and quake exposure as predictors of psychological distress following the 1999 earthquake in Turkey. J Trauma Stress. 18: 331-342.

Tainaka H, Oda H, Nakamura S, Tabuchi T, Noda T, Mito H. (1998). Workers' stress after Hanshin-Awaji earthquake in 1995-symptoms related to stress after 18 months [in Japanese; English abstract]. Sangyo Eiseigaku Zasshi. 40: 241-249.

Thabet AA, Vostanis P. (2000). Post traumatic stress disorder reactions in children of war: a longitudinal study. Child Abuse Negl. 24: 291-298.

Thomaes K, Dorrepaal E, Draijer NP, de Ruiter MB, Elzinga, BM, van, BAJ, et al. (2009). Increased activation of the left hippocampus region in Complex PTSD during encoding and recognition of emotional words: a pilot study. Psychiatry Res, 171(1): 44-53.

Tsai KY, Chou P, Chou FH, Su TT, Lin SC, Lu MK, et al. (2007). Three-year follow-up study on the relationship between posttraumatic stress symptoms and quality of life among earthquake survivors in Yu-Chi, Taiwan. J Psychiatr Res. 41(1-2): 90-96.

Tural U, Coskun B, Onder E, Corapçioğlu A, Yildiz M, Kesepara C, et al. (2004). Psychological consequences of the 1999 earthquake in Turkey. J Trauma Stress. 17(6): 451-459.

Uemoto M, Shioyama A, Koide K, Honda M, Takamiya S, Shirakawa K, et al. (2000). The mental health of school children after the Great Hanshin-Awaji Earthquake: I. Epidemiological study and risk factors for mental distress. Seishin Shinkeigaku Zasshi. 102: 459-480.

Ursano RJ, Kao T, Fullerton CS. (1992). PTSD and meaning: Structuring human chaos. J Nerv Mental Dis. 180: 756-759.

Wang X, Gao L, Shinfuku N, Zhang H, Zhao C, Shen Y. (2000). Longitudinal study of earthquake-related PTSD in a randomly selected community sample in north China. Am J Psychiatry. 57: 1260-1266.

Wolf OT (2008). The influence of stress hormones on emotional memory: relevance for psychopathology. Acta Psychol, 127(3):513-531.

Wu HC, Chou P, Chou FH, Su CY, Tsai KY, Ou-Yang WC, et al. (2006). Survey of quality of life and related risk factors for a Taiwanese village population 3 years postearthquake. Aust N Z J Psychiatry. 40: 355-361.

Yang YK, Yeh TL, Chen CC, Lee CK, Lee IH, Lee LC, et al. (2003). Psychiatric morbidity and posttraumatic symptoms among earthquake victims in primary care clinics. Gen Hosp Psychiatry. 25: 253-261.

Yeh CB, Leckman JF, Wan FJ, Shiah IS, Lu RB. (2002). Characteristics of acute stress symptoms and nitric oxide concentration in young rescue workers in Taiwan. Psychiatry Res. 112: 59-68. 


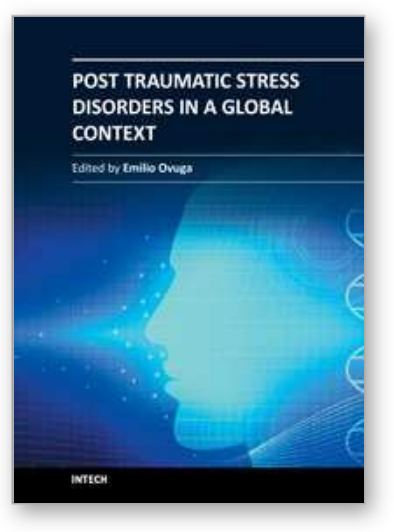

\author{
Post Traumatic Stress Disorders in a Global Context \\ Edited by Prof. Emilio Ovuga, Md, PhD
}

ISBN 978-953-307-825-0

Hard cover, 286 pages

Publisher InTech

Published online 20, January, 2012

Published in print edition January, 2012

If, as a health care or social service provider, one was called upon to help someone who has experienced terror in the hands of a hostage taker, an irate and chronically abusive spouse or parent, or a has survived a motor vehicle accident, landslide, earthquake, hurricane or even a massive flood, what would be one's priority response? What would be considered as the most pressing need of the individual requiring care? Whatever the answer to each of these questions, people who have experienced terror, suffer considerable psychological injury. Post-Traumatic Stress Disorder in a Global Context offers some answers to meet the needs of health care and socials service providers in all settings, whether in a hospital emergency room, at the war front, or natural disaster site. The take home message is, after providing emergency care, there is always a pressing need to provide mental health care to all victims of traumatic stress.

\title{
How to reference
}

In order to correctly reference this scholarly work, feel free to copy and paste the following:

Frank Huang-Chih Chou and Chao-Yueh Su (2012). Risk Factors and Hypothesis for Posttraumatic Stress Disorder (PTSD) in Post Disaster Survivors, Post Traumatic Stress Disorders in a Global Context, Prof. Emilio Ovuga, Md, PhD (Ed.), ISBN: 978-953-307-825-0, InTech, Available from: http://www.intechopen.com/books/post-traumatic-stress-disorders-in-a-global-context/risk-factors-andhypothesis-for-posttraumatic-stress-disorder-ptsd-in-post-disaster-survivors

\section{INTECH}

open science | open minds

\section{InTech Europe}

University Campus STeP Ri

Slavka Krautzeka 83/A

51000 Rijeka, Croatia

Phone: +385 (51) 770447

Fax: +385 (51) 686166

www.intechopen.com

\section{InTech China}

Unit 405, Office Block, Hotel Equatorial Shanghai

No.65, Yan An Road (West), Shanghai, 200040, China

中国上海市延安西路65号上海国际贵都大饭店办公楼 405 单元

Phone: +86-21-62489820

Fax: $+86-21-62489821$ 
(C) 2012 The Author(s). Licensee IntechOpen. This is an open access article distributed under the terms of the Creative Commons Attribution 3.0 License, which permits unrestricted use, distribution, and reproduction in any medium, provided the original work is properly cited. 